\title{
Prediction of Mechanical, Evenness and Imperfection Properties of $100 \%$ Cotton Ring Spun Yarns with Different Twist Levels
}

\author{
Gashaw Ashagre Walle ${ }^{1 a}$, Desalegn Atalie ${ }^{1 b}$, Ermiyas Tarekegn ${ }^{1 c}$, Addisu Wudneh ${ }^{1 d}$, \\ Addisu Desalegn ${ }^{1 e}$
}

RECEIVED ON 18.09.2020, ACCEPTED ON 05.05.2021

\begin{abstract}
The purpose of this research work is to develop a model to predict the effect of twist on mechanical, evenness and imperfection properties of $100 \%$ cotton ring spun yarns. Eight yarns were manufactured from 30Tex with four yarn twist increments (700, 740, 780 and 820TPM), and 15Tex with twist levels of 900, 1020, 1080 and 1140TPM (turns/meter). Except yarn count and twist level, the yarns were made from the same fiber properties and machine settings. Yarn mechanical properties such as tensile strength, elongation and abrasion resistance, evenness $(\mathrm{CVm})$ and imperfection characteristics like hairiness, neps, thin and thick places were measured and statistically analyzed. Equations were developed to predict the desired mechanical, evenness, and imperfection properties of yarns based on yarn count and twist levels. Statistical analysis showed that yarn properties are significantly influenced by count and twist level changes. The tensile strength, elongation, abrasion resistance, $\mathrm{CVm}$, hairiness and thick places of the studied yarns were significant at P-values of $0.000,0.003,0.000,0.004$, 0.000 and 0.015 respectively. Generally, as yarn twist increases, breaking strength and abrasion resistance increase, whereas elongation, hairiness, coefficient of mass variation $(\mathrm{CVm})$, thin and thick places, and nep of yarn decrease. Therefore, the formulated multiple regression equations would be useful in predicting yarn properties based on its count and twist.
\end{abstract}

Keywords: Cotton ring spun yarns, Yarn twist level, Mechanical properties, Imperfections, Yarn Evenness, Yarn property prediction

\section{INTRODUCTION}

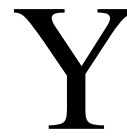
arn twist is one of the major factors which is controlled every day in textile companies. It is a crucial issue during the production of yarn directly to the market or subsequent operations because it affects yarn parameters, fabric properties, production, and final productivity. Twist binds the fibers together and creates the spiral arrangement of the fibers around the axis of the yarn [1]. Twist can be inserted in either $\mathrm{Z}$ or $\mathrm{S}$ direction by the traveler for ring frame and rotor for open-end spinning. Most yarns are spun with Z-twist. In ring spun yarn, twist is imparted on the surface of the yarn and almost all the fibers are uniformly integrated along the spiral line of twist. In contrast, in rotor spun yarn, twist is applied in the yarn core and it has wrapper fibers [2]. Twist contributes significantly to different yarn properties [1]. The impact of twist on yarn quality, production and final productivity is an established fact. Twist imparts cohesion between the fibers and contributes to prevent damage when the yarn is subjected to any

\footnotetext{
${ }^{1}$ Textile Production Research and Innovation Center, Ethiopian Institute of Textile and Fashion Technology, Bahir Dar University, Bahir Dar, Ethiopia. Email: ${ }^{a}$ gashaw15@gmail.com (Corresponding Author),

bdesalegnatalie@gmail.com, ermiastarekegnbdr@gmail.com, dwudinehaddisu339@gmail.com, eaddisudesalegn21@gmail.com
}

This is an open access article published by Mehran University of Engineering and Technology, Jamshoro under CC BY 4.0 International License. 
external force [3]. Therefore, the twisting mechanism including twist distribution and propagation has attracted an increasing interest of researchers in textiles and apparel $[4,5]$.

It is shown that yarn twist affects yarn properties and spinning efficiency of normal blended yarns [6]. Abbasi et al. [7] also found out that twist influences yarn properties, especially strength and evenness. Twisting fibers together imparts strength to the yarn. Fibers become harder to pull apart making the yarn more difficult to break. The higher the twist, the more the yarn strength till optimum twist is reached. Sreenivasan and Shankaranarayana [8] and Hadjina and Kovačević [9] studied the structure and behavior of yarns and their ultimate influence on the end-use properties of fabrics. They investigated that spun yarns with higher twist multiplier exhibit greater yarn irregularity (40-70\%). Hearle et al. [10,11] indicated that twist in any yarn cross-section is approximately inversely proportional to the number of fibers in it. A close relationship is also exhibited between fiber fracture and yarn strength, about $60 \%$ of the fibers break when the yarn strength is at its highest. To characterize yarn quality, strength is one of the main criteria and most of the previous studies focused on developing models by considering fiber properties, yarn strength and other structural parameters of yarns.

In addition, the effect of twist level on the mechanical and thermal properties of nylon 66 and polyethylene terephthalate (PET) tyre cords has been studied. The shrinkage values increase with increasing twist factor, whereas shrinks force values decrease for greige nylons and polyester cords. Adhesion and fatigue resistance increased with increasing twist factors [12].

Yarn properties such as yarn fineness, strength and evenness are affected by twist variation. Yarn evenness also has significant influence on other properties of the yarn and of the fabric made from it. To produce a uniform yarn, all fiber characteristics would have to be uniformly distributed over the whole thread. However, that is impractical due to inhomogeneity of the fiber material and by the mechanical constraints in manufacturing. An investigation indicates that fiber neps predominate, particularly fiber neps having a core mainly of immature and dead fibers, on the yarn surface distorting yarn evenness [13].

Other authors [14] studied the effect of yarn twist direction on the formability of woven fabrics and they found that unidirectional $\mathrm{Z} \& \mathrm{Z}$ twists have higher formability in comparison to those fabrics in which the warp and weft twists are opposite to each other, i.e., Z $\&$ S. Previous researchers investigated the effect of weft yarn twist level on sensorial comfort of $100 \%$ woven cotton fabrics. The results revealed that a sample developed with 920 TPM weft yarns was less slippery, rougher and less even than other fabrics made from lower twist yarns [15].

Wear in textile materials is one of a limited number of fault factors in which an object loses its usefulness and the economic implication can be of enormous value to the industry. As wear usually occurs by rubbing together of two surfaces, abrasion is often used as a general term to mean wear [16]. Abrasion properties of textile materials are affected by different factors including fiber and yarn properties [17]. Earlier researchers stated that textile materials can be unserviceable because of several different factors and one of the most important causes is abrasion. Abrasion occurs during wearing, using, cleaning or washing process and this may distort the fabric, cause fibers or yarns to be pulled out or remove fiber ends from the surface. Abrasion ultimately results in the loss of performance characteristics, such as strength, but it also affects the appearance of the fabric. There is an optimum amount of twist in a yarn to give the best abrasion resistance [18].

A number of researchers emphasized the relationship between fiber parameters and yarn properties [19-24]. There is also a great deal of literature on the impact of twist on yarn properties as well as the correlation between yarn twist and fabric behaviors. However, in this research work, a comprehensive investigation of the effects of yarn twist levels and count on mechanical, evenness and imperfection properties of $100 \%$ cotton ring spun yarns is carried out. Eight yarns with twist levels of 700, 740, 780 and 820TPM for yarn count of 30Tex and 900, 1020, 1080 and 1140TPM for 15Tex were employed for this research.

In addition, a model is developed using multiple 
regression to predict the desired mechanical and Imperfection properties of yarns based on yarn count and twist levels.

\section{MATERIALS AND METHODS}

\subsection{Materials}

Eight $100 \%$ cotton yarns were produced with counts of 30Tex and 15Tex and twist levels of 700, 740, 780 and 820TPM (turns per meter), and 900, 1020, 1080 and 1140TPM respectively using ring spinning system. The properties of cotton fibre to produce the required yarns are shown in Table 1.

\subsection{Methods}

For this study, the yarn samples having different twist levels of 700, 740, 780 and 820 turns per meter for 30Tex and 900, 1020, 1080 and 1140 for 15Tex were produced using RIETER G35 ring spinning machine and $100 \%$ cotton fiber keeping all other fiber parameters constant such as fiber origin, staple length, short fiber index, nep, trash\% and micronaire values. Yarns were conditioned at relative humidity of $65 \pm 2$ and temperature of $20 \pm 1$ for 24 hours. Ten trials were measured in all studied yarn properties.

\subsubsection{Yarn Strength and Elongation}

Tensile strength is one of the major mechanical properties of yarns. The breaking strength and elongation values of cotton yarns were tested as per ISO 2062 standard using Statimate Me+ yarn strength tester. Ten tests are measured in each yarn.

\subsubsection{Yarn Abrasion Resistance}

In weaving and knitting processes, yarns have propensity for abrasion resulting in yarn breakage. The abrasion resistance values of yarns were evaluated using Shirly yarn abrasion tester (SDL Atlas model) according to ASTM D 3412 test method. The test principle is that hard-rough surface of the roller slides across a yarn surface and abrasion cycles would be recorded at yarn breakage. The internal microprocessor and printer provide a printout of the number of revolutions of reciprocating motion achieved by each yarn before breakage.

\subsubsection{Yarn Evenness and Imperfections}

The yarns' coefficient of mass variation $(\mathrm{CVm})$ and yarn imperfections such as neps, hairiness, thick and thin places were measured using Uster Tester 5 as per ASTM D1425 standard. Ten tests were carried out for each sample of yarn twist.

\subsubsection{Data Analysis}

To determine whether any of the differences between the samples are statistically significant or not, one-way ANOVA test was performed using SPSS version 25 for windows statistical software. To predict mechanical, evenness and imperfection properties of yarns, equations were developed using multiple linear regression in Mini Lab version 19 software. The range of the variables of yarn count 5-65 Tex and twist 3001800 turns per meter have been used as an input in formulating the models.

\section{RESULTS AND DISCUSSION}

In this Section, cotton yarns with twist levels 700, 740, 780 and 820 turns per meter for 30Tex and 900, 1020, 1080 and 1140 turns per meter for 15Tex are denoted as $1,2,3,4,5,6,7$, and 8 respectively to avoid cluttered figures.

\subsection{Effect of yarn twist on tensile strength of yarns}

Fig. 1 shows that the tensile strength of yarns increased as twist increased. This is because high number of turns per meter in the yarn's longitudinal direction contributes to increasing strength since fibers are more tightly held together. Yarn made from 30Tex and twist of 700TPM had the least strength of $206 \mathrm{cN} / \mathrm{tex}$ and cotton yarn mode from the highest twist (1140 TPM) finer yarn count of 15 Tex had higher tensile strength of $277.7 \mathrm{cN} /$ tex followed by yarns made from 1080 , $1020,900,820,780$ and $740 \mathrm{TPM}$ respectively. It is

\begin{tabular}{|c|c|c|c|c|c|c|c|}
\hline \multicolumn{8}{|c|}{ Table1: Cotton Fibre Properties } \\
\hline MIC & Mat & UHML [mm] & $\mathrm{UI}(\%)$ & $\mathrm{SF}(\%)$ & $\operatorname{Str}[\mathrm{g} / \mathrm{m}]$ & $\operatorname{Elg}(\%)$ & TrGrd \\
\hline 4.12 & 0.85 & 30.24 & 83.8 & 6.5 & 28.8 & 6.7 & 3 \\
\hline
\end{tabular}

Mehran University Research Journal of Engineering and Technology, Vol. 41, No. 1, January 2022 [p-ISSN: 0254-7821, e-ISSN: 2413-7219] 
also noted that yarn fineness increases with increasing twist.

As indicated in Table 2, the statistical analysis proves that the strength of produced yarns was significantly different due to twist variation at F-value of 86.944 and P-value of 0.000 . These findings corroborate with previous research results that showed yarn manufactured with higher twist and finer count has better yarn strength compared with lower twist levels and coarser counts [6].

\subsection{Effect of twist $n$ elongation of yarns}

The findings reveal that yarn elongation was affected by yarn twist levels at F-value of 26.540 and P-value of 0.003 . Fig. 2 demonstrates that yarns produced from 15Tex with yarn twist of 1140TPM had lower extension than yarns made from coarser yarn count of 30Tex with twist of 700TPM. This general trend of decreasing elongation as twist increases is because of the fact that when twist imparted to the yarn increases, the fibers inside it become more oriented and tightened together and are not allowed to extend much from the original position. Therefore, it is suggested that before producing the yarn, end use should be considered.

\subsection{Effect of twist on abrasion resistance of yarns}

As high twist levels are inserted to the yarn, the fibers are firmly held and tightened together and cannot

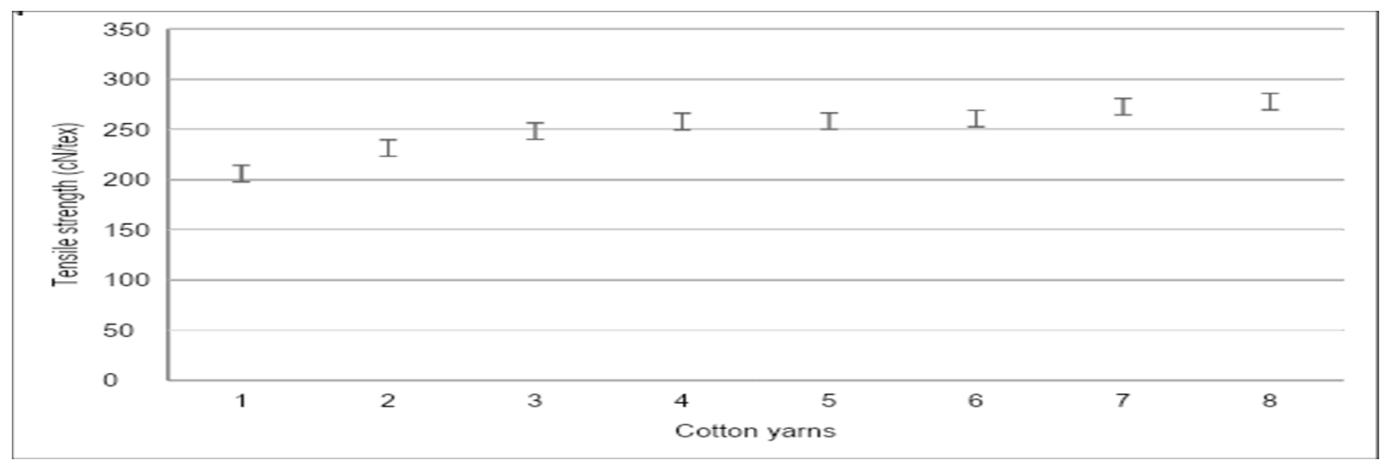

Fig. 1: Twist level and strength of yarns

\begin{tabular}{|c|c|c|c|c|c|}
\hline \multicolumn{7}{|c|}{ Table 2: Analysis of Variance Results of Yarn Strength } \\
\hline & Sum of quares & df & Mean Square & F & Sig. \\
\hline Between Groups & 819.087 & 7 & 117.012 & 86.944 & .000 \\
\hline Within Groups & 96.900 & 72 & 1.346 & & \\
\hline Total & 915.987 & 79 & & & \\
\hline
\end{tabular}

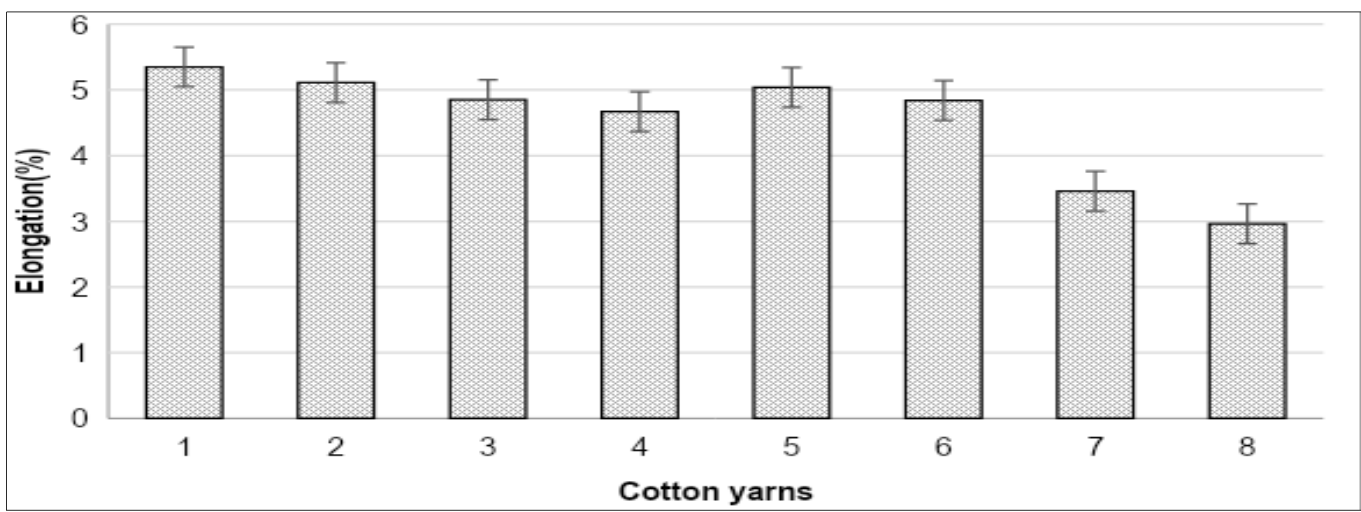

Fig. 2: Twist level and elongation of yarns 


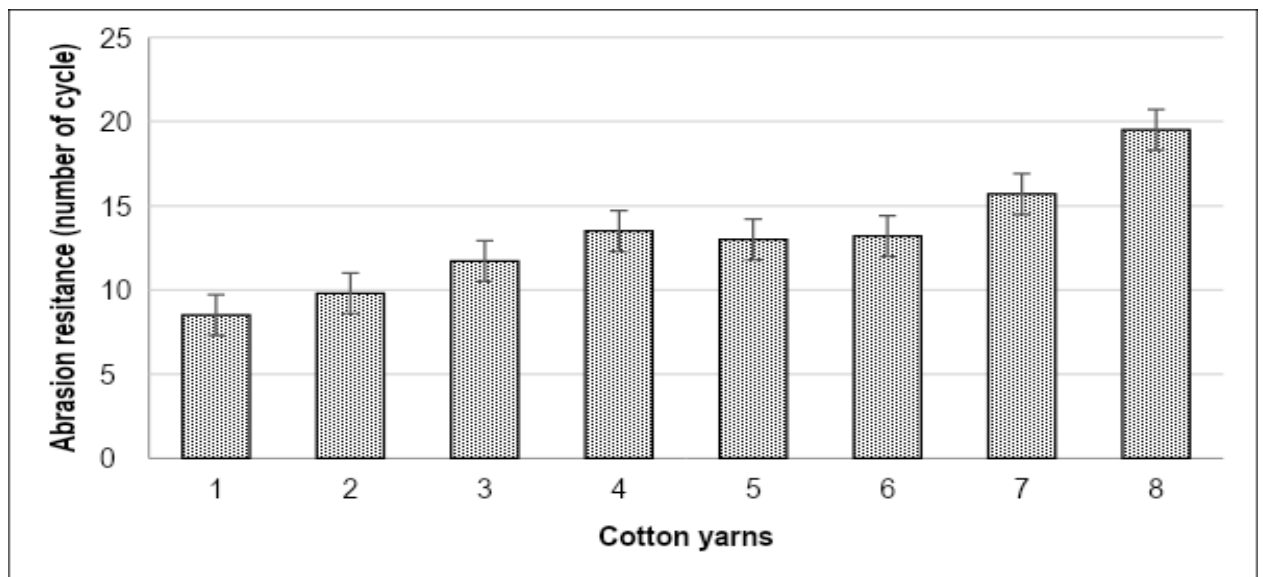

Fig. 3: Twist level and the abrasion resistance of yarns

\begin{tabular}{|c|c|r|r|r|r|r|}
\hline \multicolumn{7}{|c|}{ Table 3: Descriptive statistical analysis of yarn abrasion resistance } \\
\hline $\begin{array}{c}\text { Yarn type } \\
\text { (TPM) }\end{array}$ & $\mathrm{N}$ & Mean & $\begin{array}{c}\text { Std. } \\
\text { Deviation }\end{array}$ & $\begin{array}{c}\text { Std. } \\
\text { Error }\end{array}$ & Minimum & Maximum \\
\hline 700 & 10 & 8.5000 & 1.08012 & .34157 & 7.00 & 10.00 \\
\hline 740 & 10 & 9.8000 & 1.31656 & .41633 & 8.00 & 12.00 \\
\hline 780 & 10 & 11.7000 & 1.15950 & .36667 & 10.00 & 13.00 \\
\hline 820 & 10 & 13.5000 & 1.08012 & .34157 & 12.00 & 15.00 \\
\hline 900 & 10 & 13.0000 & .66667 & .21082 & 12.00 & 14.00 \\
\hline 1020 & 10 & 13.2000 & 1.03280 & .32660 & 12.00 & 15.00 \\
\hline 1080 & 10 & 15.7000 & 1.33749 & .42295 & 13.00 & 18.00 \\
\hline 1140 & 10 & 19.5000 & 1.43372 & .45338 & 17.00 & 22.00 \\
\hline
\end{tabular}

easily break. The previous study by Atalie et al. [15] reported similar concept. In contrast, in lower twist yarns, fibers are loosely grouped owing to less turns per meter and have high tendency to fringe out by friction with abrasive paper and leads to yarn breakage quickly. Due to this, the yarn abrasion resistance increased as the twist levels increased as presented in Fig. 3. At low twist, fibers can easily be removed from the yarn so that it is gradually reduced in diameter. As seen in Fig. 3, yarn produced from 15Tex with yarn twist of 1140TPM has greater abrasion resistance. The general trend indicates that abrasion resistance decreases as twist levels decrease.

Table 3 shows descriptive statistical analysis of yarn abrasion resistance and standard deviations were almost similar for all type of yarns. Besides the average abrasion cycles, the minimum and maximum abrasion cycles are illustrated in Table 2. According to one-way ANOVA results, the studied yarns' abrasion resistance was significantly changed at F-value of 18.691 and $\mathrm{P}$-value of 0.000 .

\subsection{Effect of twist on yarn coefficient of mass variation $\left(\mathrm{CV}_{\mathrm{m}}\right)$}

The statistical analysis proves that coefficient of mass variation $\left(\mathrm{CV}_{\mathrm{m}}\right)$ is significantly affected by yarn twist at F-value of 16.347 and P-value of 0.004. The spinner tries to produce a yarn with the highest possible degree of homogeneity and the evenness of the yarn mass is of paramount importance. The unit length mass variation due to variation in fibre assembly results in change of yarn properties. The coefficient of mass variation $\left(\mathrm{CV}_{\mathrm{m}}\right)$ can be determined extremely accurately by electronic means. Non-uniformity in different yarn properties exists due to variation of twist levels. In order to produce an absolutely regular yarn, all fibre characteristics would have to be uniformly distributed over the whole thread. As twist increases, cotton yarn properties change because fibers are spirally arranged around the yarn axis. As shown in Fig. 4, as twist increases, coefficient of mass variation $\left(\mathrm{CV}_{\mathrm{m}}\right)$ of a cotton yarn decreases and the yarn becomes more regular. Conversely, when twist inserted to the 
yarn is lower, the percentage of coefficient of mass variation $\left(\mathrm{CV}_{\mathrm{m}}\right)$ increases throughout the length of the yarn. These findings agree with Jahan's [25] research results.

\subsection{Effect of yarn twist on yarn hairiness}

As the twist levels in a yarn increase, the yarn becomes more compact because the fibers are held more tightly together giving a harder feel to the yarn. A fabric made from a high twist yarn will, therefore, feel harder and will also be thinner. On the other hand, a fabric which is produced from a low twist yarn will have a soft handle and it will be thicker. Fig. 5 shows that yarn twist and hairiness are inversely proportional, i.e., when the twist inserted to the yarn increases, the hairiness of the yarn decreases. This is because the tendency of protruding fibers is less when TPM increases in the yarn and vice versa. Analysis of variance of the produced yarns indicates a significant difference in hairiness at $\mathrm{P}$-value of 0.000 .
As twist level increases, so does the smoothness of the yarn due to decreasing number of protruding fibers on a given yarn surface. In terms of measurement, hairiness corresponds to the total length of protruding fibers per unit length of one centimeter. The results of this research are confirmed with the earlier report [26].

\subsection{Effect of twist on yarn neps, and thick and thin places}

Yarn thin places $(-50 \%)$, thick places $(+50 \%)$ and neps $(+200 \%)$ are important yarn parameters, and significantly influence yarn appearance and penetration of a dye or finish [27]. The thicker yarn region will tend to be deeper in shade than the thinner ones and, if a visual fault appears in a pattern on the fabric, the pattern will tend to be emphasized by the presence of colour or by some variation in a visible property such as crease-resistance [28].

As shown in Fig. 6, yarn thin $(-50 \%)$ and thick places $(+50 \%)$ as well as neps $(+200 \%)$ decreased with

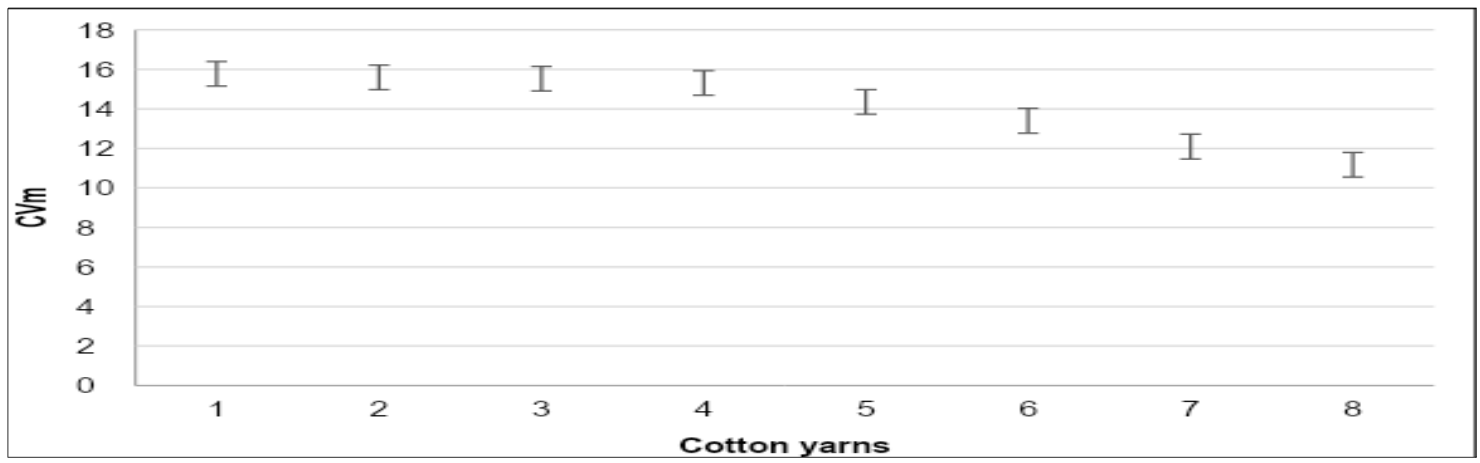

Fig. 4: Twist and coefficient of mass variation $(\mathrm{CVm})$ of the yarns

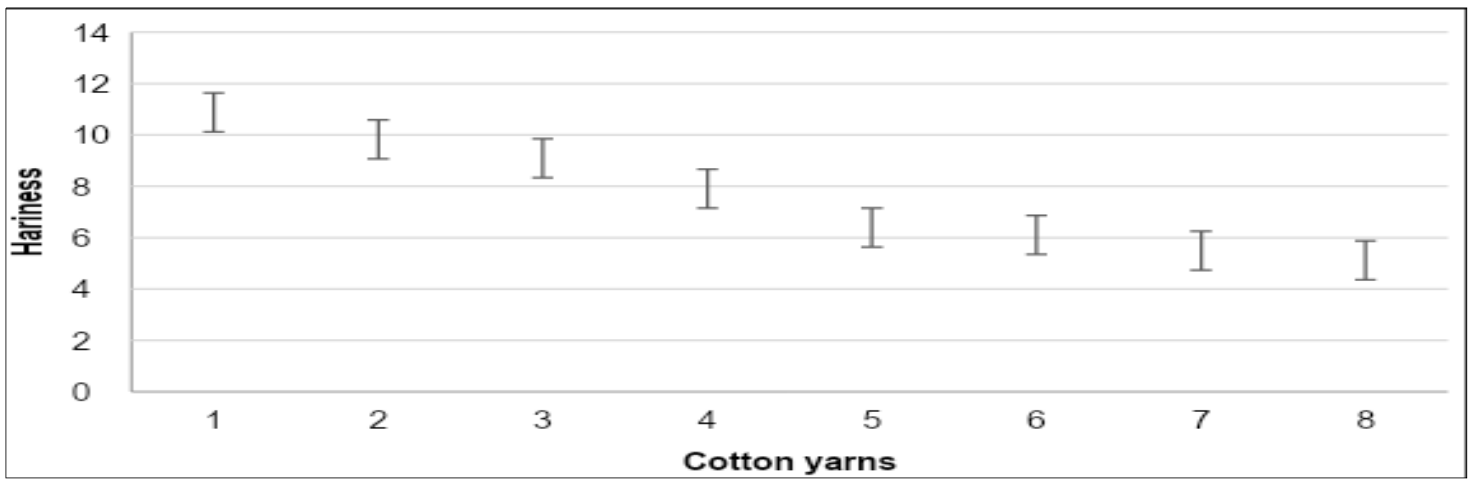

Fig. 5: Twist and hairiness of the yarns 
$(+50 \%)$ as well as neps $(+200 \%)$ decreased with increasing twist factor. ANOVA results prove that yarns made from different twist levels are significantly different in yarn thick places and neps at $\mathrm{P}$-values of 0.015 and 0.000 , where $\alpha=0.005$. However, yarn thin places did not show significant change at F-value of 17.894 and P-value of 0.406. Generally, as twist increases imperfection of a cotton yarn decreases and the yarn becomes more regular. On the other hand, when twist inserted to the yarn is lower, the percentage of imperfections or faults (such as thin and thick places, and neps) increases leading to reduced yarn appearance grade.

\subsection{Multiple regression equations}

Prediction of yarn properties is very important and can save time, testing cost and eliminate unnecessary loss of test specimen since prediction is non-destructive. Equations (1) to (5) are developed using multiple regression. To prove the effectiveness of the equations, commercial cotton yarns of known count and twist were made from the same fibre content and manufacturing system. As shown in Table 4, the

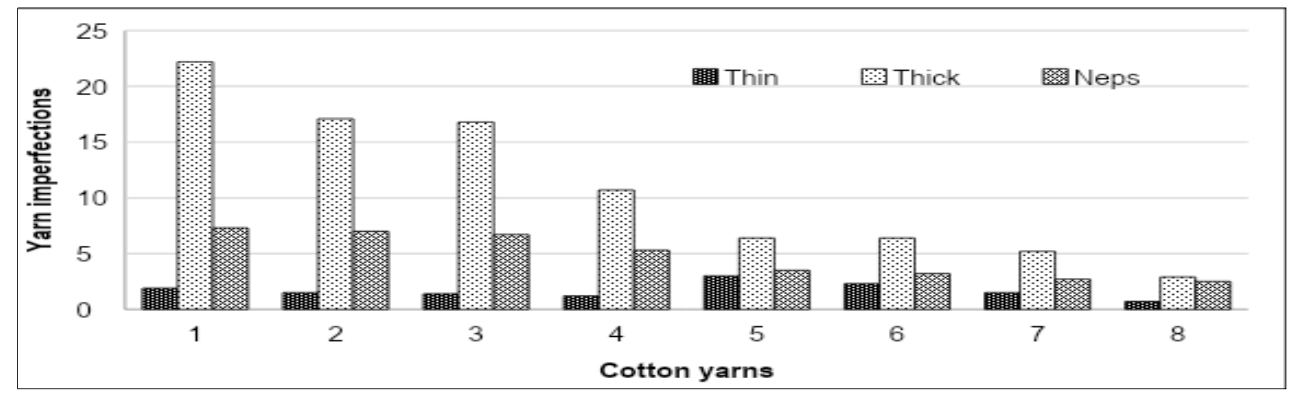

Fig. 6: Impact of twist on yarns thin and thick places, and neps

\begin{tabular}{|l|l|l|l|}
\hline \multicolumn{4}{|c|}{ Table 4 Measured and calculated values of yarn properties } \\
\hline Yarn samples & Properties & Measured & Calculated \\
\hline \multirow{4}{*}{ 30Tex (700TPM) } & Tensile strength & 206.02 & 222.73 \\
\cline { 2 - 4 } & Elongation (\%) & 5.35 & 5.5 \\
\cline { 2 - 4 } & Abrasion (cycles) & 8.5 & 9.15 \\
\cline { 2 - 4 } & $\mathrm{CV}_{\mathrm{m}}$ & 15.78 & 16.2 \\
\cline { 2 - 4 } & Hairiness & 10.75 & 9.97 \\
\hline \multirow{4}{*}{ 15Tex (1140TPM) } & Tensile strength & 277.74 & 283.67 \\
\cline { 2 - 4 } & Elongation & 2.96 & 3.19 \\
\cline { 2 - 4 } & Abrasion (cycles) & 19.5 & 18.38 \\
\cline { 2 - 4 } & CV & 11.18 & 11.56 \\
\cline { 2 - 4 } & Hairiness & 5.12 & 4.81 \\
\hline \multirow{4}{*}{$\begin{array}{l}\text { Control yarn } \\
\text { 14 Tex (1200TPM) }\end{array}$} & Tensile strength & 258.92 & 263.36 \\
\cline { 2 - 4 } & Elongation (\%) & 4.23 & 3.98 \\
\cline { 2 - 4 } & Abrasion (cycles) & 15.62 & 15.15 \\
\cline { 2 - 4 } & CV & 14.21 & 13.24 \\
\cline { 2 - 4 } & Hairiness & 5.61 & 6.73 \\
\hline & Tensile strength & 287.52 & 292.2 \\
\cline { 2 - 4 } & Elongation (\%) & 3.24 & 2.78 \\
\cline { 2 - 4 } & Abrasion (cycles) & 18.5 & 19.9 \\
\cline { 2 - 4 } & CV & 12.36 & 10.89 \\
\cline { 2 - 4 } & Hairiness & 4.24 & 4.19 \\
\hline
\end{tabular}


measured and calculated yarn values are comparable. The difference between them is called prediction error. This implies regression analysis is a statistical tool in the formulation of a mathematical model depicting the relationship among variables which can be used for the purpose of prediction of the values of dependent variable given the values of the independent variables. Therefore, a slight difference between the measured and calculated values is expected in the model [29].

Strength $\left(\frac{\mathrm{cN}}{\text { tex }}\right)=96.5+0.736 . X_{1}+0.1545 . X_{2}$

Elongation $(\%)=14.224-0.0937 . \mathrm{X}_{1}-0.008447 \mathrm{X}_{2}$

Abrasion $($ cycles $)=-17.95+0.2303 . X_{1}+0.02884 X_{2}$

$\operatorname{CVm}(\%)=24.89-0.0226 . \mathrm{X}_{1}-0.01140 . \mathrm{X}_{2}$

Hairness $=14.13+0.0752 . X_{1}-0.009162 . X_{2}$

where $\mathrm{X}_{1}$ is yarn count (Tex) and $\mathrm{X}_{2}$ is twist/meter.

\section{CONCLUSION}

This study investigated the effect of twist on mechanical, evenness and imperfection properties of yarns. Eight $100 \%$ cotton ring spun yarns were manufactured from 30Tex with four yarn twist increments (700, 740, 780 and 820TPM), and 15Tex with twist levels of 900, 1020, 1080 and 1140TPM. Mechanical characteristics (such as tensile strength, elongation and abrasion resistance), yarn evenness $\left(\mathrm{CV}_{\mathrm{m}}\right)$, yarn imperfections including hairiness, neps $(+200 \%)$, thin places $(-50 \%)$ and thick places $(+50 \%)$ were measured and analyzed. Multiple regression was used to develop equations to predict the yarn properties based on yarn count and twist levels. The statistical analysis proved that as levels of twist increase, breaking strength and abrasion resistance of a yarn increase, whereas elongation, hairiness, coefficient of mass variation $\left(\mathrm{CV}_{\mathrm{m}}\right)$, thin and thick places and neps of a yarn decrease. The developed equations are effective to predict yarn mechanical, evenness and imperfection properties, and they would be helpful for yarn manufacturers.

\section{ACKNOWLEDGMENTS}

The study was conducted at Ethiopian Institute of Textile and Fashion Technology (EiTEX), Bahir Dar
University. The authors are grateful for Bahir Dar Textile S.C., particularly Mr. Nardos Getnet, for allowing manufacturing of yarns.

\section{REFERENCES}

1. Rao R. N., "Estimation of single yarn twist and the relation between the estimated and mechanical twists", Textile Research Journal, Vol. 36, No. 1, pp. 65-71, 1966.

2. Ernst H., "Rotor Spinning: The Rieter Manual of Spinning", Vol. 5, p. 95, 2014.

Available at:

https://www.rieter.com/services/expertise/therieter-manual-of-spinning [Last assessed on 15th August 2020].

3. Tang H. B., Xu B. G., Tao X. M., "A new analytical solution of the twist wave propagation equation with its application in a modified ring spinning system," Textile Research Journal, Vol. 80, No. 7, pp. 636-641, 2010.

4. Mercier A. A., Schoffstall C. W., "Effect of twist on cotton yarns", Bureau of Standards Journal of Research, Vol. 1, pp. 733-750, 1928.

5. Turner A. J., Venkataraman V., "1-The foundations of yarn-strength and yarn-extension: Part V-The prediction of the spinning value of a cotton from its fibre-properties," Journal of the Textile Institute Transactions, Vol. 25, No. 1, pp. T1-T48, 1934.

6. Simpson J., Fiori L. A., "How Yarn Twist Affects Yarn Uniformity and Imperfections," Textile. Research Journal, Vol. 45, No. 2, pp. 136-137, 1975.

7. Abbasi S. A., Peerzada M. H., Jhatial R. A., "Characterization of low twist yarn: effect of twist on physical and mechanical properties," Mehran University Research Journal of Engineering and Technology, Vol. 31, No. 3, pp. 553-558, 2012.

8. Sreenivasan K., Shankaranarayana K. S., "Twist and Tension as Factors in Yarn Characteristics," Textile Research Journal, Vol. 31, No. 8, pp. 746753, 1961.

9. Hadina J., Kovačević S., "Influence of yarn twist on the texture of fabric," Tekst. časopis za Tekst. Tehnol. i konfekciju, Vol. 47, No. 9, pp. 447-452, 
1998.

10. Hearle J. W. S., El-Behery H. M. A. E, Thakur V.M., "6-The mechanics of twisted yarns: Tensile properties of continuous-filament yarns", Journal of the Textile Institute Transactions, Vol. 50, No. 1, pp. T83-T111, 1959.

11. Hearle J. W. S., Thakur V. M., "4-The breakage of twisted yarns", Journal of the Textile Institute Transactions, Vol. 52, No. 2, pp. T49-T63, 1961.

12. Aytac A., Yilmaz B., Deniz V., "Effect of twist level on tyre cord performance", Fibers and Polymers, Vol. 10, No. 2, pp. 221-225, 2009.

13. Jehle V., "Analyse der Faservereinzelung im Kardierprozeß zur Vermeidung einer Faserschädigung", 2002.

14. Alamdar-Yazdi A., Bidoki S. M., "The effect of yarn twist direction on the formability of woven fabrics", Journal of the Textile Institute Transactions, Vol. 101, No. 8, pp. 739-745, 2010.

15. Atalie D., Ferede A., Rotich G. K., "Effect of weft yarn twist level on mechanical and sensorial comfort of $100 \%$ woven cotton fabrics", Fashion and Textiles, Vol. 6, No. 1, 2019.

16. Xu B. G., Tao X. M., "Techniques for Torque Modification of Singles Ring Spun Yarns", Textile Research Journal, Vol. 78, No. 10, pp. 869-879, 2008.

17. Barella A., "Textiles," J. Text. Inst., vol. 21, pp. 205-224, 1930.

18. Xu B., Tao X., Leung C. S., “A comparative study of cotton knitted fabrics and garments produced by the modified low twist and conventional ring yarns," Fibers and Polymers, Vol. 11, No. 6, pp. 899-904, 2010.

19. Yang S., Gordon S., "Accurate prediction of cotton ring-spun yarn quality from high-volume instrument and mill processing data by", Textile Research Journal, Vol. 87, No. 9, pp. 1025-1039, 2016.

20. Üreyen M.E., Kadoğlu H. "The Prediction of Cotton Ring Yarn Properties from AFIS Fibre Properties by Using Linear Regression Models," Fibres and Textiles in Eastern Europe, Vol. 15, No. 4, pp. 63-67, 2007.

21. Üreyen M.E. Kadoğlu H. "Regressional Estimation of Ring Cotton Yarn Properties from
HVI Fiber Properties", Textile Research Journal, Vol. 76, No. 5, pp. 360-366, 2006.

22. Ghanmi H., Ghith A. Benameur T. , "Response Surface Regression Models for Prediction of Ring Spun Yarn Properties", Research Journal of Textile and Apparel, Vol. 19 No. 4, pp. 1-10, 2015.

23. Amin M., Ullah M.A. Akbar A., "Identification of Cotton Properties to Improve Yarn Count Quality by Using Regression Analysis", Pakistan Journal of Scientific and Industrial Research, Vol. 57, No. 3, pp. 167-171, 2014.

24. Üreyen M.E., Gürkan P.. "Comparison of artificial neural network and linear regression models for prediction of ring spun yarn properties. I. Prediction of yarn tensile properties", Fibers and Polymers, Vol. 9, No. 1, pp. 87-91, 2008.

25. Jahan I., "Effect of Fabric Structure on the Mechanical Properties of Woven Fabrics", Advanced Research in Textile Engineering, Vol. 2, No. 2, 2017.

26. Cheng L., Fu P., Yu X., "Relationship Between Hairiness and the Twisting Principles of Solospun and Ring Spun Yarns", Textile Research Journal, Vol. 74, No. 9, pp. 763-766, 2004.

27. Shad S. S., Javed M. I., Azam M., "Imperfections and hairiness of $24 \mathrm{~s}$ cotton yarn affected by air jet nozzle pressures and winding speeds at autocone", Pakistan Journal of Life and Social Sciences, Vol. 2, No. 2, pp. 118-123, 2004.

28. Abbasi I. U., "Effect of some mechanical variables of the Edera Spin Tester on the optimum production of quality yarn", M. Sc. Thesis, Department of Fibre Technology, University of Agriculture, Faisalabad, 1994.

29. Mangat A.E., Hes L., Bajzik V., Mazari A., "Thermal absorptivity model of knitted rib fabric and its experimental verification", Autex Research Journal, Vol. 18, No. 1, pp. 20-27, 2018. 